\title{
Usage of Onomatopoeic and Mimetic Words in Vietnamese-Korean Bilingual Compared to Korean Monolingual Families
}

\author{
Seonkyeong Kim, Su Hwa Yoo, Jihye Jang, Yunju Cho, Yoonhee Yang, Dongsun Yim \\ Department of Communication Disorders, Ewah Womans University, Seoul, Korea
}

Correspondence: Dongsun Yim, PhD Department of Communication Disorders, Ewha Womans University, 52 Ewhayeodae-gil, Seodaemun-gu, Seoul 03760, Korea

Tel: $+82-2-3277-6720$

Fax: +82-2-3277-2122

E-mail: sunyim@ewha.ac.kr

Received: April 5, 2019

Revised: May 8, 2019

Accepted: May 8, 2019

This work was supported by the Ministry of Education of the Republic of Korea and the National Research Foundation of Korea (No. NRF-2018S1A3A2075274).

\begin{abstract}
Objectives: This study investigates the differences in the patterns of using onomatopoeic and mimetic words in Vietnamese-Korean bilingual and Korean monolingual mothers and children. Methods: Twenty-one Vietnamese-Korean (V-K) families (13 children and 8 mothers) and 25 Korean (K) families (14 children and 11 mothers) participated in this study. Children were aged from 3;0 to 6;1 (in year;month), and there were no significant group differences in their vocabulary scores. We used a picture-explaining task (which is divided into the object task and the sound-action task) to investigate how participants perform differently when describing pictures depicting objects and movements. Additionally, we conducted a picture-association task to choose the correct picture from four options through listening to the auditory stimuli of recorded words as quickly as possible. Results: V-K bilingual mothers showed significantly lower performance on the picture-explaining object and sound-action task than $\mathrm{K}$ monolingual mothers. But, there was no significant difference between $\mathrm{V}-\mathrm{K}$ bilingual and $\mathrm{K}$ monolingual children in the picture-explaining object task. In the picture-explaining sound-action task, however, $\mathrm{V}-\mathrm{K}$ bilingual children showed lower performance than $\mathrm{K}$ monolingual children. In the picture-association task, there were significant differences in accuracy and reaction times between $\mathrm{V}-\mathrm{K}$ bilingual and $\mathrm{K}$ monolingual mothers and children. Conclusion: Although no significant differences were found in the language abilities of the two children groups, both mothers and children in bilingual and monolingual groups showed significant differences in using onomatopoeic and mimetic words. Therefore, onomatopoeic and mimetic words are a unique characteristic of Korean and are important for efficient communication.
\end{abstract}

Keywords: Onomatopoeic and mimetic words, Vietnamese-Korean bilingual family, Korean monolingual family, Multicultural family, Mother's language ability
국제 결혼의 증가로 인해 매년 다문화 가구 수가 증가하는 가운 데, 다문화 가정에 대한 사회적 관심이 높아지고 있다. 2017년 다문 화 인구동태 통계(Statistics Korea, 2018)에 따르면, 국내에서 이루 어지는 전체 혼인 중 다문화 혼인의 비중은 $8.3 \%$ 로, 21,917 건에 달 한다. 특히, 다문화 혼인 가운데 아내가 외국인인 경우가 $65.0 \%$, 남 편이 외국인인 경우가 $19.6 \%$ 로 다문화 가정에서 아내가 외국인 및 귀화자로 구성된 유형이 약 $3.31 \%$ 더 많다. 이들은 한국 사회에서 점진적으로 증가해온 국내 거주 외국인 중 상당히 큰 비율을 차지
하고 있기 때문에, 이러한 다문화 가정의 엄마와 자녀의 한국 적응 을 도모하는 다각적인 모색이 꾸준히 요구되고 있다. 2000년대 초 반에는 중국, 일본, 필리핀 등에서 이주해온 여성들이 다수를 이루 었으나, 최근에는 베트남에서 이주해온 여성들도 급격히 늘어나 중 국 58,108 명에 이어 두 번째로 많은 수인 41,877 명을 차지한다고 보 고되기도 하였다(Park \& Lee, 2012). 또한, 2017년 다문화 인구동태 통계(Statistics Korea, 2018)에서는 다문화 혼인을 한 외국인 및 귀 화자 아내의 출신 국적이 베트남(27.7\%)인 경우가 중국(25.0\%)보다 
도 더 많았음을 보고하기도 하였다. 이들은 한국에서 가정을 이루 며 살아가면서 언어가 달라서 생기는 의사소통 어려움과 문화적 차이로 인한 적응 문제를 가장 주요한 어려움으로 꼽았다(Kwon \& Cha, 2006; Lee, 2016).

언어를 배운다는 것은 언어가 쓰이는 나라의 역사, 문화, 사회적 맥락까지 통합적으로 습득하는 것을 의미하기 때문에 다문화 가정 의 어머니와자녀에게 큰 도전이 될 수 있다. 특히, 한국어의 경우 의 성어와 의태어가 다른 언어에 비해 매우 다양한 것으로 보고되며, 중요한 요소로 간주된다. 국립국어원(National Institute of the Korean Language)이 1999년 출간한 표준국어대사전에 따르면, 한국 어의 의성어와 의태어의 수는 약 5,800 개이다. 비교적 의성어와 의 태어의 수가 많은 것으로 알려진 일본어의 경우 그 수가 약 2,500 개 인 것을 감안할 때(Bae \& Park, 2012), 한국어는 다른 언어에 비해 의성어와 의태어의 수가 월등하게 많다. Kambara와 Tsukada (2010) 의 연구에서는 의성어의 사용이 언어에 따라 다양하고, 몇몇 아시 아 언어, 특히 일본어와 한국어는 많은 의성어가 있다고 보고하고 있다. 의성어와 의태어는 단순한 어휘가 아니라 사람의 감정과 정서 를 나타낼 수 있기 때문에, 이를 학습하는 것은 단순히 언어만 배우 는 것이 아니라 해당 국가의 특성을 반영하는 정서와 문화를 함께 이해하는 것이라 할 수 있다(Kim, 2015). 즉, 한국어에서의 의성어 와 의태어는 한국인 특유의 감정이나 느낌을 표현하는 유용한 수단 이라는 점에서 효용성이 매우 높다고 볼 수 있다. 그러나, 외국인 언 어학습자의 경우, 한국어 음운체계로 나타난 의성어 및 의태어에 대해 한국인만큼 그 형태와 의미의 긴밀함을 인식하기에는 다소 어 렵다고 볼수 있다(Bae, 2006). 특히 의태어는 한국어에서 발달한 것 으로 그 종류와 쓰임이 다양하여 외국인 학습자가 자신의 모국어 에 없는 형태와 의미를 학습하는 데 어려울 수 있다(Bae, 2006).

의성의태어는 세부적으로 의성어를 사람이나 사물의 소리를 흥 내 낸 말로, 의태어를 모양, 태도, 행동 등의 양태를 묘사한 말로 각 각 분류하기도 하지만, 의성의태어를 청각, 시각, 촉각, 미각 통각 등 인간의 감각적 인식의 근거가 되는 오감에서 나오는 언어의 형태로 통칭하기도 한다(National Institute of the Korean Language, 1999). 실제로 의성어와 의태어를 따로 분류하는 것은 사용한 사람의 사 용 의도와 실질적 의미를 정확하게 파악해야 하는 매우 어려운 과 정이며 국어학자들에게조차도 조심스러운 일에 속한다(Kim \& Yun, 2017). 그러므로, 의성어와 의태어가 의성의태어의 하위 개념 어 범주 안에 속하는 것으로 보고, “의성의태어”로 통칭하기도 한 다(Kim \& Yun, 2017).

의성의태어는 상태, 움직임, 느낌과 감정, 그리고 그것을 재미있 고, 생생한 방식으로 표현할 수 있게 한다(Kambara \& Tsukada,
2010). 특히 의성의태어는 아동에서 성인에 이르기까지 누구에게 나 직관적으로 그리고 감각적으로 이해 가능한 언어이며 특히, 초 기 아동기의 어린 아동들이 새로운 단어를 학습하는 데에 도움을 주는 역할을 한다(Thiessen, Hill, \& Saffran, 2005). 아동이 일상생 활에서 쉽게 접할 수 있는 동물 관련 소리나 사물의 움직임 등의 의 성의태어는 아동 언어의 $50 \%$ 를 차지하고 있을 정도로 많이 사용하 고 있으며 학습이나 산출 면에서 아동에게 흥미를 주는 언어이기 때문이다(Kim, Yang, \& Lim, 2014). 아동은 성인뿐만 아니라 또래 와의 의사소통에서도 빈번하게 의성의태어를 사용하며 영유아 옹 알이의 음절 반복이 가진 리드미컬한 표출 음성 또한 의성의태어의 양상을 띠고 있다(Osaka, 1999). 즉, 운율적 특성이 내포되어 있어 아동의 주의를 끌고, 정서발달에도 긍정적인 영향을 준다(Cooper \& Aslin, 1990; Fernald, 1992; Taumoepeau \& Ruffman, 2008).

또한, 이러한 의성의태어는 한국어에서 아동지향어의 중요한 특 징이며, 청자에게 민감한 특수한 언어이다. 특히, 한국의 어머니들 은 성인에게 말할 때보다 아동에게 말할 때 더 빈번하게 의성의태 어를 사용하는데, 이는 의성의태어가 아동지향어(child-directed speech)의 특징을 지니고 있음을 보여준다(Bae \& Park, 2012). 아동 지향어의 특징은 문화와 언어에 상관없이 나타나는 보편적 현상이 지만, 각 언어권마다 얼마나 자주 사용되는지, 사물을 어떻게 명명 하고 행동을 표현하는지와 같은 세부적인 속성들은 언어권 또는 문화권마다 큰 차이가 있다(Fernald et al., 1989; Grieser \& Kuhl, 1988; Mazuka, Kondo, \& Hayashi, 2008). 그러나, 한국어가 미숙한 다문화 가정의 어머니들은 자신의 어휘에 의성의태어는 다른 어휘 유형에 비해 부족할 수 있고, 습득하기에도 비교적 어려운 것으로 보고되기도 한다(Bae \& Park, 2012). 의성의태어는 아주 어린 시기 에 습득되는 어휘에 속하는 특성이 있어서 모국어 화자들에게는 아주 친숙한 특성이 있지만, 오히려 성인이 되어서 해당 언어의 의 성의태어까지 습득하기에는 우선순위에서 밀려날 수 있는 것이다. 더 나아가, 같은 다문화 가정일지라도 의성의태어가 비교적 풍부한 일본어를 모국어로 하는 어머니에 비해 동남아시아권의 언어를 모 국어로 하는 어머니들은 자신의 모국어에서 의성의태어의 비율 자 체가 낮기 때문에 한국으로 이주한 이후에도 자녀에게 의성의태어 를 사용할 가능성은 낮아질 것으로 추론된다(Bae \& Park, 2012). $\mathrm{Bae}$ 와 Park (2012)의 연구에서도 한국어를 모국어로 하지 않는 외 국인 양육자와아동의 대화에서 의성의태어의 사용이 현저히 낮았 음을 보고하였다. 이와 같이 아동지향어로서의 의성의태어의 결여 나 부족한 활용 등이 실제로 한국에서의 다문화 가정 아동들의 언 어발달에 불이익을 미친다면, 의성의태어의 적절한 활용을 도모할 수 있도록 다문화 가정 아동의 언어발달 촉진 자료로 활용될 수 있 
다(Bae \& Park, 2012).

특히, 다문화 가정의 자녀들은 외국인 어머니의 오랜 한국생활로 표면적으로는 의사소통 및 언어발달에 큰 문제를 갖고 있지 않는 것처럼 나타난다고 할지라도, 동음이의어(Jang, Jeong, \& Hwang, 2014), 조사산출(Choi, Jeong, \& Hwang, 2012)과 같은 질적인 측면 의 언어 평가에서 유의하게 낮은 수행을 보인 선행연구 결과들이 존재한다. 따라서 본 연구에서는 위와 같은 선행연구와 자료에 근 거하여, 국내의 다문화 가정에서 많은 비중을 차지하고 있는 베트 남어-한국어 이중언어 사용 다문화 가정과 한국어를 모국어로 사 용하는 단일문화 가정의 어머니와 아동 간에 의성의태어 사용 양 상과 능력의 차이를 살펴보고자 한다.

구체적인 연구 질문은 다음과 같다.

1) 베트남어-한국어를 사용하는 다문화 가정과 한국어를 사용 하는 단일문화 가정 어머니와 아동의 그림과제(사물과제, 소 리동작과제) 수행에서 의성의태어 능력에 집단 간 유의미한 차이가 있는가?

2) 베트남어-한국어를 사용하는 다문화 가정과 한국어를 사용하 는 단일문화 가정 어머니와아동의 연상과제 수행에서 의성의태 어 능력(정확도, 반응속도)에 집단간 유의미한차이가 있는가?

\section{연구방법}

\section{연구대상}

본 연구에서는 대한민국에 거주하는 만 3-6세 베트남-한국 다문 화 가정의 어머니와 아동 21 명(어머니 8 명, 아동 13 명), 한국 단일문 화 가정의 어머니와 아동 25 명(어머니 11 명, 아동 14 명), 총 46 명이 참여하였다.
본 연구과제를 실행하기에 앞서, 아동의 언어발달에 대한 정보와 가정의 배경에 대한 정보를 확인하기 위해 부모 보고(Korean Brief Parent Report, KBPR; Han \& Yim, 2018)를 어머니에게, 한국어 수 용·표현어휘력검사(Receptive \& Expressive Vocabulary Test, REVT; Kim, Hong, Kim, Jang, \& Lee, 2009)를 아동에게 각각 실시 하였다. 그 결과, (1) 어머니 보고를 통해 아동의 현재 언어능력, 행 동패턴, 활동 선호도, 그리고 가족력에 이상이 없음을 확인하였고 ( $p>$ >05), (2) 아동의 수용어휘력( $p>.05)$ 과 표현어휘력 $(p>.05)$ 에 베 트남어-한국어를 사용하는 다문화 가정의 아동과 한국어를 사용 하는 단일문화 가정의 아동의 차이가 없음을 확인하였다.

또한, 각 아동 어머니의 연령, 교육년수, 다문화 가정 어머니의 한 국 거주년수를 확인하였다. 다문화 아동 어머니의 연령은 30.13세 $(\mathrm{SD}=4.36)$, 한국 단일문화 아동 어머니의 연령은 34.91 세 $(\mathrm{SD}=$ 4.23)이었으며 통계적으로 유의한 차이가 있었다 $(p<.05)$. 다문화 아동 아버지의 연령은 48.00 세(SD=4.54), 한국 단일문화 아동 아 버지의 연령은 37.18 세( $\mathrm{SD}=4.85)$ 로 통계적으로 유의한 차이가 있 었다 $(p<.05)$. 다문화 아동 어머니의 교육년수는 11.38 년(SD $=2.88)$, 한국 단일문화 아동 어머니의 교육년수는 14.91 년 $(\mathrm{SD}=2.49)$ 로 통 계적으로 유의한 차이가 있었으며 $(p<.05)$, 한국 단일문화 아동 아 버지의 교육년수는 13.75 년(SD = 2.49), 한국 단일문화 아동 아버지 의 교육년수는 15.27 년(SD=1.85)로 통계적으로 유의한 차이는 없 었다 $(p>.05)$. 또한, 다문화 가정 어머니 8 명의 한국 거주년수에 대 한 정보는 4-6년 미만 2명, 6-10년 미만 5명, 10년 이상 1명이었다. 세 부적인 내용은 Table 1에 제시하였다.

\section{연구자료}

베트남어-한국어를 사용하는 다문화 가정의 어머니와 아동, 한

Table 1. Participants' characteristics

\begin{tabular}{|c|c|c|c|c|c|}
\hline Characteristic & BI_C $(\mathrm{N}=13)$ & MO_C $(N=14)$ & $\mathrm{Bl} \_\mathrm{P}(\mathrm{N}=8)$ & MO_P $(N=11)$ & $F$ \\
\hline Age (mo) & $53.15(12.48)$ & $53.50(13.23)$ & - & - & .005 \\
\hline \multicolumn{6}{|l|}{ REVT } \\
\hline Receptive vocabulary & 41.54 (19.03) & 53.43 (20.89) & - & - & 2.377 \\
\hline Expressive vocabulary & $44.69(19.44)$ & $54.36(21.35)$ & - & - & 1.505 \\
\hline KBPR & $49.69(4.96)$ & $50.79(5.71)$ & - & - & .028 \\
\hline Mother's age (yr) & - & - & $30.13(4.36)$ & $34.91(4.23)$ & $5.78^{*}$ \\
\hline Father's age (yr) & - & - & $48.00(4.54)$ & $37.18(4.85)$ & $24.27^{* *}$ \\
\hline Mother's education (yr) & - & - & $11.38(2.88)$ & $14.91(1.87)$ & $10.60^{* *}$ \\
\hline Father's education (yr) & - & - & $13.75(2.49)$ & $15.27(1.85)$ & 2.35 \\
\hline
\end{tabular}

Values are presented as mean (SD).

$\mathrm{BI} \_\mathrm{C}=$ bilingual children; $\mathrm{MO} \_\mathrm{C}=$ monolingual children; $\mathrm{B} \_$P $=$bilingual parents; $\mathrm{MO} \_\mathrm{P}=$ monolingual parents; $\mathrm{REVT}=$ Receptive and Expressive Vocabulary Test $($ Kim, Hong, Kim, Jang, \& Lee, 2009); KBPR= Korean Brief Parent Report (Han \& Yim, 2018).

${ }^{*} p<.05,{ }^{* *} p<.01$. 
국어를 사용하는 단일문화 가정의 어머니와 아동의 의성의태어 사 용 양상을 비교하기 위해 두 가지 과제(그림과제, 연상과제)를 실행 하였다. 본 연구에서 활용한 그림과제와 연상과제는 연구자가 연구 의 목적에 부합하도록 수정하여 개발한 과제이다. 그림과제는 $\mathrm{Bae}$ 와 Park (2012)의 연구에서 사용한 사물그림과 동작그림 과제를 참 고하였고, 연상과제는 Lee (2016)의 연구에서 사용한 선택형 연상 과 장면 연상과제를 참고하여 개발하였다. 본 연구의 연구과제에서 사용한 의성의태어 목록은 Apppendix 1에 제시하였다.

\section{그림과제(사물과제, 소리동작과제)}

그림과제는 사물과제와 소리동작과제의 두 가지 유형으로 나누 어 진행된다. 사물 그림을 설명할 때와 소리 및 움직임이 있는 그림 을 설명할 때 의성의태어 사용 양상이 다르게 나타나는지 비교하 기 위한 목적으로 두 가지 그림과제를 실시하였다. 즉, 사물과제는 밥, 책, 의자와 같은 사물을 보고 이를 자세히 설명하는 과제이다. 소리동작과제는 주어지는 그림(소리 또는 동작 관련)을 보고 이를 자세히 설명하는 과제이다. 예를 들어, 강아지가 짖고 있는 그림에 서는 ‘멍멍', 별이 빛나고 있는 그림에서는 '반짝반짝'을 사용하여 그림을 설명하는지를 보는 것이다. 움직이지 않는 정지된 사물을 설명해야 하는 사물과제에 비해 소리동작과제에서 더 많은 의성의 태어가 산출될 것이라 가정하였다.

단, 베트남어에도 한국어보다는 적은 수이지만 의성의태어가 존 재한다고 알려져 있기 때문에 베트남과 한국에서 공통으로 사용 되는 의성의태어 목록과 한국에서만 사용되는 의성의태어 목록을 따로 제작하였다. 사물과제와 소리동작과제 모두 연습문항 5 문항, 본 문항 15 문항의 총 20 문항으로 구성되어 있다. 본 문항을 실시하 기 전 충분한 예시와 함께 연습문항을 진행하여 대상자에게 충분 한 이해를 시킨 후본 문항을 진행하였다.

연구절차는 다음과 같다. 먼저, 그림과제를 통하여 주 양육자인
어머니와 아동 모두에게 자극그림(사물 그림, 동작 그림)을 제시하 고 대상에게 이를 자세히 묘사하도록 지시하였다. 이때 대상의 자 극그림 묘사에 나타난 의성의태어의 사용빈도를 측정하였다. 다문 화 가정의 경우, 그들의 모국어와 한국어 모두에서의 의성의태어 사용빈도를 측정하였다. 과제에 사용되는 그림(사물과제, 소리동 작과제)은 Figure 1에 제시하였다.

\section{연상과제}

연상과제는 소리동작과제와 동일하게 베트남과 한국에서 공통 적으로 사용되는 의성의태어 목록과 한국에서만 사용되는 의성의 태어 목록을 따로 제작하였다. 따라서 베트남 다문화 가정에서 과 제를 실행할 때에는 목표 의성의태어를 들려줄 때 베트남 가정의 어머니와 아동에게는 베트남어와 한국어가 모두 제시되는 녹음한 파일을 들려주었으며, 한국 가정의 경우 한국어로 의성의태어를 제 시하였다. 이 과제 또한 각 가정의 주양육자인 어머니와 아동이 모 두 과제를 수행하도록 하였다. 연상과제도 그림과제와 마찬가지로 연습문항 5 문항, 본 문항 15 문항의 총 20 문항으로 구성되어 있다. 본 문항을 실시하기 전 충분한 예시와 함께 연습문항을 진행하여 대상자에게 충분한 이해를 시킨 후 본 문항을 진행하였다.

연구절차는 다음과 같다. 먼저, 연구에 참여하는 모든 어머니와 아동들이 소리로 제시되는 목표 자극(의성의태어)을 듣고 컴퓨터 모니터에 제시되는 4 개의 그림 중 목표자극과 연상되는 한 개의 그 림을 고르도록 하였다. 목표 자극(의성의태어) 예시는 Figure 1에 제시하였다.

그림을 정확하게 선택했는지의 여부를 보는 정확도(accuracy)와 함께, 정반응한 문항에 대하여 얼마나 빠르게 그림을 선택했는지 를 보는 반응시간(reaction time)도 함께 측정하였다. 연상과제의 그림 예시는 Figure 2에 제시하였다.

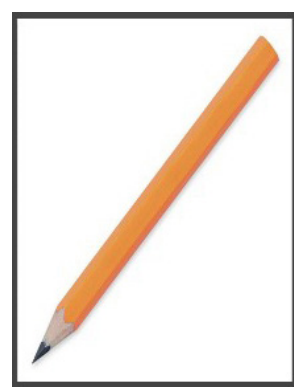

Pencil

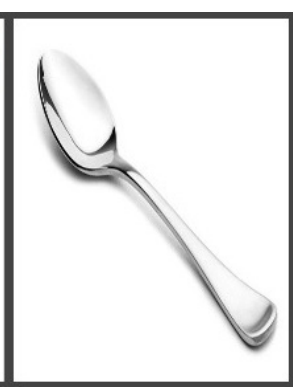

Spoon

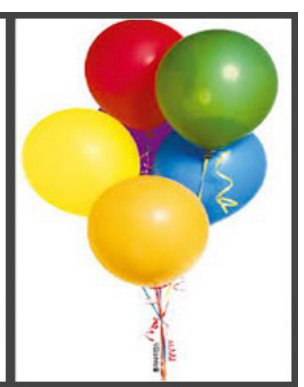

Balloon
(A)

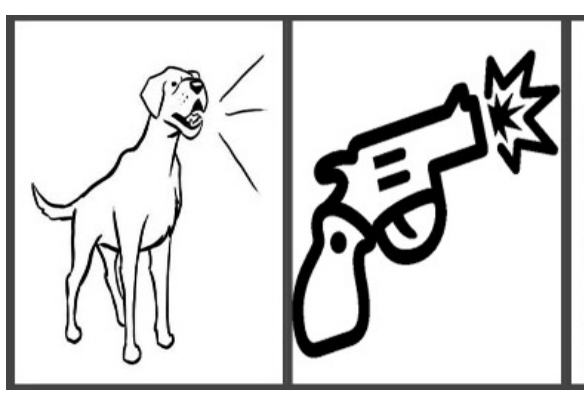

Bow-wow

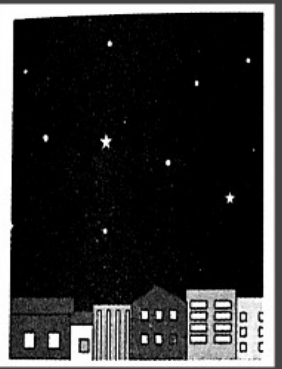

Twinkle-twinkle (B)

Figure 1. Examples of picture explaining task: $(\mathrm{A})$ object task and $(\mathrm{B})$ sound-action task. 


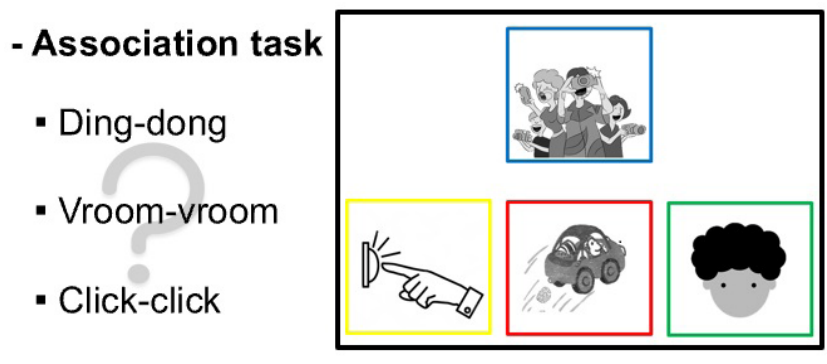

Figure 2. Examples of association task.

\section{자료분석 및 결과처리}

본 연구의 과제 수행 분석을 위해 각 과제의 원점수는 정반응한 문항에 총 문항을 나누어 100 을 곱하여 \%점수로 산출하였다. 그림 과제(사물과제, 소리동작과제) 및 연상과제의 그룹 간, 과제 간차이 를 살펴보기 위해 일원분산분석(one-way ANOVA) 및 이원분산분 석(two-way ANOVA)을 사용하였다. 본 연구의 모든 통계분석은 SPSS version 19 (IBM SPSS, Armonk, NY, USA)를 사용하였다.

\section{연구결과}

\section{그림과제(사물과제, 소리동작과제)에서의 집단 간 의성의태어 양상 비교}

다문화 가정 어머니와 단일문화 가정 어머니의 수행 비교

베트남어-한국어 사용 다문화 가정의 어머니와 한국어 사용 단 일문화 가정 어머니의 그림과제(사물과제, 소리동작과제)에서의 수 행을 살펴보았다. 그 결과, 사물과제에서는 다문화 가정의 어머니 와 단일문화 가정의 어머니의 수행 차이가 유의하였으며 $\left(F_{(1,17)}=\right.$ $5.243, p<.05)$, 한국어 사용 단일문화 가정의 어머니는 17.58 점 (SE $=4.04)$, 베트남어-한국어 사용 다문화 가정의 어머니는 3.33점 $(\mathrm{SE}=4.73)$ 을 받았다.

소리동작과제에서도 다문화 가정의 어머니와 단일문화 가정 어 머니의 수행 차이는 유의하였다 $\left(F_{(1,17)}=88.470, p<.01\right)$. 한국어 사 용 단일문화 가정의 어머니는 80.30 점 $(\mathrm{SE}=3.96)$, 베트남어-한국어 사용 다문화 가정의 어머니는 22.92점 $(\mathrm{SE}=4.64)$ 을 받았다. 한편, 단어목록 조건(V-K, K only)에 따른 수행의 차이는 유의하지 않았 으나( $p>.05)$, 단어목록 조건 및 집단의 이차상호작용은 유의한 것 으로 나타났다 $\left(F_{(1,17)}=8.741, p<.01\right)$. 즉, 베트남어-한국어 사용 다 문화 가정의 어머니는 베트남과 한국에서 공통으로 사용되는 의성 의태어 조건에서 30.00 점 $(\mathrm{SE}=4.64)$, 한국어에서만 사용되는 의성 의태어 조건에서 15.83 점 $(\mathrm{SE}=4.93)$ 을 받아 유의하게 $\mathrm{V}-\mathrm{K}$ 조건에 서 더 높은 수행을 보인 반면, 한국어 사용 단일문화 가정의 어머니
Table 2. Scores (\%) of picture explaining tasks in mothers group

\begin{tabular}{lrcc}
\hline Condition & V-K mother & K mother & $F$ \\
\hline Object & $3.33(4.73)$ & $17.58(4.04)$ & $5.243^{*}$ \\
Sound-action (V-K) & $30.00(4.64)$ & $76.37(5.04)$ & $88.470^{* *}$ \\
Sound-action (K only) & $15.83(4.93)$ & $84.24(4.21)$ & \\
\hline
\end{tabular}

Values are presented as mean (SE).

$\mathrm{V}-\mathrm{K}=$ Vietnamese-Korean bilingual; $\mathrm{K}$ only $=$ Korean only.

${ }^{*} p<.05,{ }^{* *} p<.01$.

Table 3. Scores (\%) of picture explaining tasks in children group

\begin{tabular}{lrcc}
\hline Condition & V-K children & K children & $F$ \\
\hline Object & $1.03(1.34)$ & $2.86(1.29)$ & .970 \\
Sound-action (V-K) & $21.03(4.58)$ & $37.14(4.41)$ & $7.741^{*}$ \\
Sound-action (K only) & $35.38(5.33)$ & $53.81(5.14)$ & \\
\hline
\end{tabular}

Values are presented as mean (SE).

$\mathrm{V}-\mathrm{K}=$ Vietnamese-Korean bilingual; $\mathrm{K}$ only=Korean only.

${ }^{*} p<.05,{ }^{* *} p<.01$.

는 베트남-한국 공통 사용 의성의태어 조건에서는 76.37점 ( $\mathrm{SE}=5.04)$, 한국어에서만 사용되는 의성의태어 조건에서 84.24점 $(\mathrm{SE}=4.21)$ 을 받아 두 조건 모두에서 상대적으로 높은 수행을 보였 으며, 사후분석 결과, 조건 간 수행 차이가 통계적으로 유의하지는 않았다 $(p>.05)$.

다문화 가정 아동과 단일문화 가정 아동의 수행 비교

베트남어-한국어 사용 다문화 가정의 아동과 한국 단일문화 가 정 아동의 그림과제(사물과제, 소리동작과제)에서의 수행을 확인 하였다. 그 결과, 사물과제에서는 다문화 및 단일문화 가정의 아동 의 수행차이는 유의하지 않았다 $(p>.05)$. 즉, 한국어 사용 단일문화 가정의 아동은 2.86 점 $(\mathrm{SE}=1.29)$, 베트남어-한국어 사용 다문화 가 정의 아동은 1.03 점 $(\mathrm{SE}=1.34)$ 을 받았다.

소리동작과제에서는 다문화 가정의 아동과 단일문화 가정 아동 의 수행 차이가 유의하였다 $\left(F_{(1,25)}=7.741, p<.05\right)$. 한국어 사용 단 일문화 가정의 아동은 45.48 점 $(\mathrm{SE}=4.31)$, 베트남어-한국어 사용 다문화 가정의 아동은 28.21 점(SE=4.47)을 받았다. 단어목록 조건 (V-K, K only)에 따른 수행의 차이 또한 유의하였다( $p<.05)$. 아동 들은 베트남과 한국에서 공통으로 사용되는 의성의태어 조건에서 29.08점(SE=3.18)을 받은 것과 비교하여 한국어에서만 사용되는 의성의태어 조건에서 44.60 점 $(\mathrm{SE}=3.18)$ 을 받아 더 높은 수행을 보 였다. 한편, 단어목록 조건 및 집단의 이차상호작용은 유의하지 않 았다 $(p>.05)$. 이에 따른 결과를 Tables 2 와 3 에 제시하였으며, 그림 과제에서의 전반적 결과를 Figure 3 에 제시하였다. 
Object task

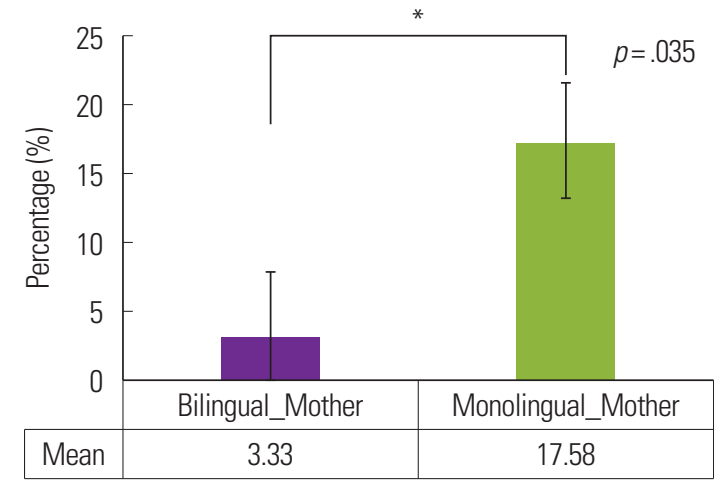

Sound-action task

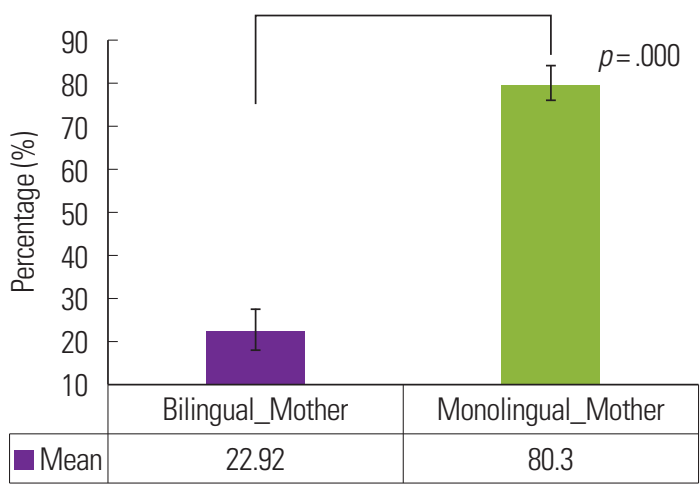

Object task

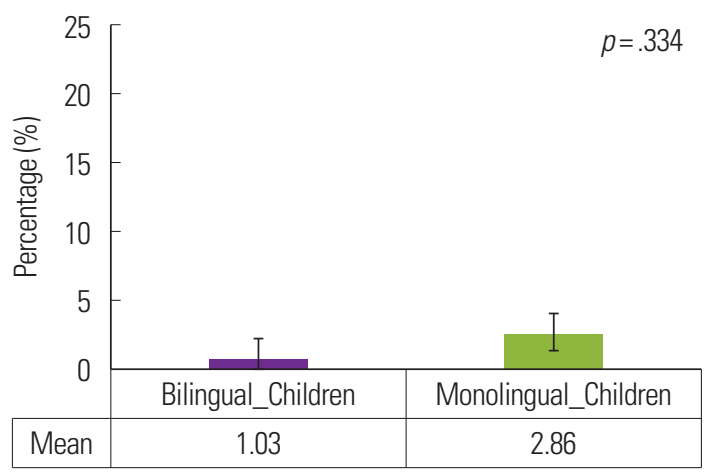

(B)

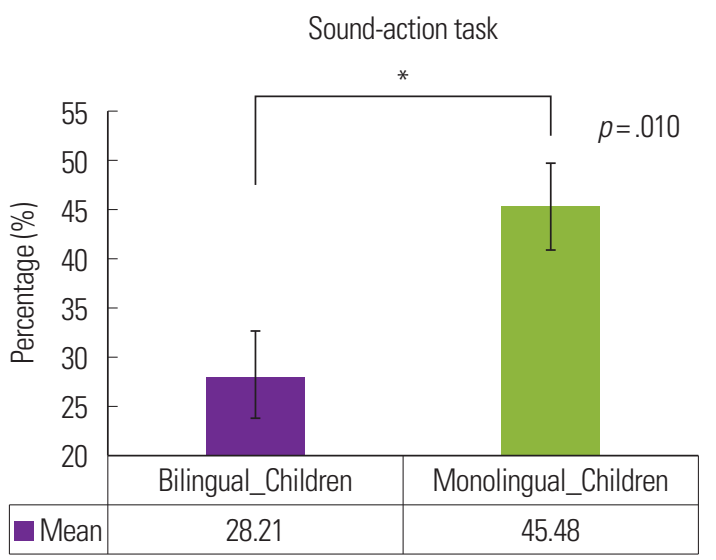

(D)

Figure 3. Accuracy of picture explaining (object, sound-action) tasks in mothers $(A, C)$ and children (B, D). * $p<.05$.

\section{연상과제에서의 집단 간 의성의태어 양상 비교}

다문화 가정 어머니와 단일문화 가정 어머니의 수행 비교

베트남어-한국어 사용 다문화 가정의 어머니와 한국어 사용 단 일문화 가정 어머니의 연상과제에서의 수행을 살펴보았다. 정확도 측면에서 살펴본 결과, 연상과제에서는 다문화 가정의 어머니와 단 일문화 가정의 어머니의 수행 차이가 유의하였으며 $\left(F_{(1,17)}=11.392\right.$, $p<.01)$, 한국어 사용 단일문화 가정의 어머니는 100.00 점( $\mathrm{SE}=$ 2.96), 베트남어-한국어 사용 다문화 가정의 어머니는 84.58 점 $(\mathrm{SE}=3.48)$ 을 받았다. 그러나, 단어목록 조건(V-K, K only)에 따른 수행의 차이는 유의하지 않았으며( $p>.05)$, 단어목록 조건 및 집단 의 이차상호작용 또한 유의하지 않았다 $(p>.05)$.

반응속도 측면에서 살펴본 결과, 연상과제에서 다문화 가정의 어 머니와 단일문화 가정의 어머니 수행차이가 유의하였다 $\left(F_{(1,17)}=\right.$ $35.415, p<.01)$. 즉, 한국어 사용 단일문화 가정의 어머니의 반응속 도는 $1,487.41 \mathrm{~ms}(\mathrm{SE}=308.59)$, 베트남어-한국어 사용 다문화 가정 의 어머니의 반응속도는 $4,317.50 \mathrm{~ms}(\mathrm{SE}=361.85)$ 로 한국어 사용 단일문화 가정 어머니의 반응속도가 유의하게 더 빨랐다. 한편, 단
어목록 조건(V-K, K only)에 따른 수행의 차이는 유의하지 않았으 나 $(p>.05)$, 단어목록 조건 및 집단의 이차상호작용은 유의하게 나 타났다 $\left(F_{(1,17)}=5.150, p<.05\right)$. 이에 사후분석을 실시한 결과, 베트 남어-한국어 사용 다문화 가정의 어머니는 베트남과 한국에서 공 통으로 사용되는 의성의태어 조건에서 $3,803.63 \mathrm{~ms}(\mathrm{SE}=395.02)$, 한국어에서만 사용되는 의성의태어 조건에서 $4,831.38 \mathrm{~ms}(\mathrm{SE}=$ 430.79)의 반응속도를 보였으며 통계적으로 두 조건의 차이는 유의 하지 않았으나 $(p>.05)$, 한국어 사용 단일문화 가정의 어머니는 베 트남-한국 공통 사용 의성의태어 조건에서는 $1,569.09 \mathrm{~ms}(\mathrm{SE}=$ 336.87), 한국어에서만 사용되는 의성의태어 조건에서 $1,405.73 \mathrm{~ms}$ $(\mathrm{SE}=367.38)$ 의 상대적으로 더 빠른 수행을 보여 조건 간 수행 차이 역시 통계적으로 유의하게 나타났다 $(p<.05)$. 이에 대한 결과를 Table 4에 제시하였다.

\section{다문화 가정 아동과 단일문화 가정 아동의 수행 비교}

베트남어-한국어 사용 다문화 가정의 아동과 한국 단일문화 가 정 아동의 연상과제에서의 수행을 확인하였다. 정확도 측면에서 살 
Table 4. Accuracy and response time of association tasks in mothers group

\begin{tabular}{llccc}
\hline & & V-K mother & K mother & $F$ \\
\hline Accuracy (\%) & V-K & $90.00(2.43)$ & $100.00(2.07)$ & $11.392^{* *}$ \\
& K only & $79.17(5.20)$ & $100.00(4.44)$ & \\
Reaction time (ms) & V-K & $3,803.63(395.02)$ & $1,569.09(336.87)$ & $35.415^{* *}$ \\
& K only & $4,831.38(430.79)$ & $1,405.73(367.38)$ & \\
\end{tabular}

Values are presented as mean (SE).

$\mathrm{V}-\mathrm{K}=$ Vietnamese-Korean bilingual; $\mathrm{K}$ only $=$ Korean only. ${ }^{*} p<.05,{ }^{* *} p<.01$.

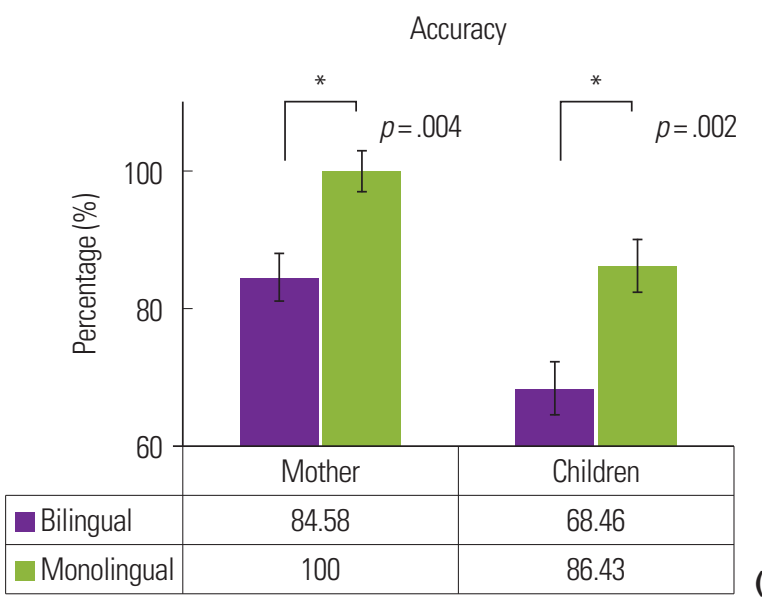

(A)

Figure 4. (A) Accuracy and (B) response time of association tasks. ${ }^{*} p<.05$.

펴본 결과, 연상과제에서는 다문화 및 단일문화 가정의 아동의 수 행차이는 유의하였다 $\left(F_{(1,17)}=11.764, p<.01\right)$. 즉, 한국어 사용 단일 문화 가정의 아동은 V-K 조건에서 89.05점(SE= 5.31), K only 조건 에서 83.81점( $\mathrm{SE}=3.74)$ 을 받았으며, 베트남어-한국어 사용 다문화 가 정의 아동은 $\mathrm{V}-\mathrm{K}$ 조건에서 70.77점(SE=5.51), $\mathrm{K}$ only 조건에서 66.15점 $(\mathrm{SE}=3.89)$ 을 받았다. 그러나, 단어목록 조건 $(\mathrm{V}-\mathrm{K}, \mathrm{K}$ only $)$ 에 따른 수행의 차이는 유의하지 않았으며( $p>.05)$, 단어목록 조건 및 집단의 이차상호작용 또한 유의하지 않았다( $p>.05)$.

반응속도 측면에서 살펴본 결과, 연상과제에서 다문화 가정의 아동과 단일문화 가정의 아동 간 수행차이가 유의하였다 $\left(F_{(1,25)}=\right.$ $7.398, p<.05)$. 즉, 한국어 사용 단일문화 가정 아동의 반응속도는 $\mathrm{V}-\mathrm{K}$ 조건에서 3,534.79 ms ( $\mathrm{SE}=508.86)$, K only 조건에서 3,495.14 $\mathrm{ms}$ ( $\mathrm{SE}=473.97)$ 이었으며, 베트남어-한국어 사용 다문화 가정 아동 의 반응속도는 V-K 조건에서 $5,379.39 \mathrm{~ms}(\mathrm{SE}=528.07)$, K only 조 건에서 $5,293.46 \mathrm{~ms}(\mathrm{SE}=508.86)$ 로 한국어 사용 단일문화 가정 아 동의 반응속도가 유의하게 더 빨랐다. 한편, 단어목록 조건(V-K, K only)에 따른 수행의 차이 및 단어목록 조건 및 집단의 이차상호작 용은 유의하지 않았다( $p>.05)$. 이에 대한 결과를 Table 5에 제시하 였으며, 연상과제에서의 전반적 결과를 Figure 4 에 제시하였다.
Table 5. Accuracy and response time of association tasks in children group

\begin{tabular}{llccc}
\hline & & V-K children & K children & $F$ \\
\hline Accuracy (\%) & V-K & $70.77(5.51)$ & $89.05(5.31)$ & $11.764^{* *}$ \\
& K only & $66.15(3.89)$ & $83.81(3.74)$ & \\
Reaction time (ms) & V-K & $5,379.39(528.07)$ & $3,534.79(508.86)$ & $7.398^{*}$ \\
& K only & $5,293.46(508.86)$ & $3,495.14(473.97)$ &
\end{tabular}

Values are presented as mean (SE).

$\mathrm{V}-\mathrm{K}=$ Vietnamese-Korean bilingual; $\mathrm{K}$ only $=$ Korean only.

${ }^{*} p<.05,{ }^{* *} p<.01$

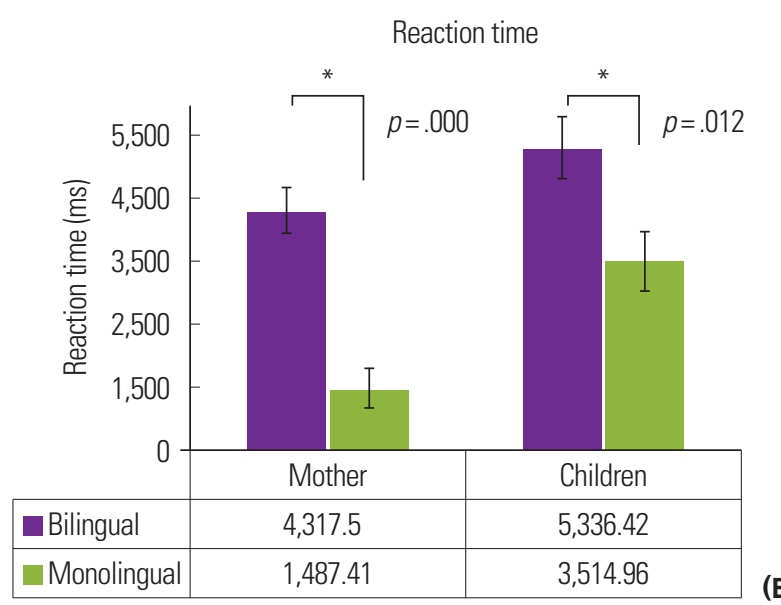

(B)

\section{논의 및 결론}

본 연구에서는 베트남어-한국어 이중언어 사용 다문화 가정과 한국 가정의 어머니와 아동의 의성의태어 과제 수행의 차이, 단어 목록 조건에 따른 수행차이를 살펴보고자 하였다. 이에 대한 논의 는 다음과 같다.

첫째, 다문화 가정 어머니와 한국 가정 어머니의 그림과제 및 연 상과제 수행 결과, 그림과제의 세부과제인 사물과제 및 소리동작과 제, 그리고 연상과제(정확도, 반응속도)에서 모두 다문화 가정의 어 머니의 수행이 한국 가정 어머니의 수행에 비해 유의하게 낮았다. 특히, 움직임이 없는 정지된 사물을 설명하는 사물과제에서도 한 국 가정의 어머니들은 의성의태어를 훨씬 더 많이 사용한 반면, 다 문화 가정의 어머니는 의성의태어를 거의 사용하지 않았다. 이는 베트남을 포함한 동남아시아 출신의 어머니들의 모국어에서 한국 어에 비해 의성의태어의 수가 많지 않아, 이들이 한국에 이주한 이 후에도 의성의태어를 사용할 가능성이 낮아질 것으로 보고한 선행 연구와 일치한다(Bae, 2006; Bae \& Park, 2012). 단어목록 조건에 따라, 베트남어-한국어에 모두 존재하는 의성의태어 목록과 한국 어에만 존재하는 의성의태어 목록 및 집단의 이차상호작용이 유의 
함에 따라 실시한 사후분석을 통해서는, 다문화 가정의 어머니가 베트남어-한국어에 모두 존재하는 단어목록 조건에서 한국어 단 어목록 조건에 비해 높은 점수를 받았지만, 한국어 사용 단일문화 가정의 어머니는 두 조건 모두에서 상대적으로 높은 수행을 보였 다. 자신의 모국어에서 더 다양하게, 더 많이 의성의태어를 사용하 는 한국의 어머니들은 어떤 유형의 의성의태어에도 관계없이 일관 적으로 의성의태어를 많이 산출하는 것으로 분석된다. 자신의 모 국어인 한국어에는 다른 언어에 비해 더욱 다양한 의성의태어가 존재하기 때문이다(Bae, 2006; Bae \& Park, 2012; Kambara \& Tsu$\mathrm{kada}, 2010)$. 반면, 다문화 가정의 어머니는 자신의 언어에서도 존 재하는 의성의태어일 경우 상대적으로 더 많이 산출하는 것으로 나타난다. 자신의 모국어에 없는 한국어 고유의 의성의태어 형태와 의미를 학습하는 데에는 상대적으로 어려움이 있는 것으로 분석된 다(Bae, 2006). 이는 특히 연상과제 수행에서 정확도뿐만 아니라 반 응속도에서도 다문화 가정의 어머니가 한국 가정의 어머니에 비해 유의하게 더 긴 것으로 나타났는데, 이는 의성의태어를 정확히 표 현하는 것뿐만 아니라 정확하게 인식하고 이해하는 것에도 더 오랜 시간이 걸리는 것으로 분석된다. 이는 외국인 한국어 학습자로서 한국어 고유의 의성의태어를 학습하는 데에 언어적, 문화적 차이 가 유의미한 영향을 미쳤을 것으로 추론된다.

둘째, 다문화 가정 아동과 한국 가정 아동의 연구과제 수행에서 는, 그림과제의 사물과제 수행 시 집단 간 유의미한 차이가 나타나 지 않았던 반면, 그림과제의 소리동작과제 및 연상과제(정확도, 반 응속도)에서는 모두 다문화 가정 아동이 한국 가정 아동에 비해 유 의하게 부족한 수행을 보였다. 이는 본 연구의 다문화 및 단일문화 가정 아동이 표준화검사인 REVT와 부모보고인 KBPR을 통해 언 어능력에서 차이가 없는 것으로 나타났음에도 불구하고, 사물이 그려진 그림을 설명하는 사물과제를 제외한 모든 과제에서 의성의 태어 관련 수행에 유의하게 부족함을 나타낸 것이다. 이는 의성의 태어가 풍부하게 사용되는 한국어와는 달리, 베트남어를 모국어 로 사용하는 다문화 가정의 어머니들의 낮은 의성의태어 사용으로 인해 다문화 가정의 아동 또한 의성의태어를 자연스럽게 사용하는 데에 어느 정도 제한적일 수 있다. 또한, 다문화 가정의 아동은 자신 의 어머니와는 다르게 베트남과 한국에서 공통으로 사용되는 의 성의태어 조건의 수행이 한국에서만 사용되는 의성의태어 조건에 비해 유의하게 높지는 않았다. 즉, 이미 한국 문화권에서 자라나고 있는 다문화 가정 아동의 의성의태어 능력의 발달이 어머니의 모국 어에서도 사용되는 의성의태어 조건과는 어느 정도 별개로 이루어 졌을 가능성을 시사한다. 또한, 다문화 가정의 아동의 한국어 습득 시기가 아동기에 속하는 만큼, 아동지향어의 특징을 지니는 의성의
태어의 경우 각 아동의 한국어 학습과정과 경험에 의해 습득된 것 으로 어머니에 비해 비교적 효율적으로 습득할 수 있는 잠재력을 지니고 있지만, 또래 한국 단일문화 가정 아동에 비해서는 정서 및 문화적으로 의성의태어를 풍부하게 사용될 수 가정 내 환경은 제 한적이다. 즉, 해당 언어권의 의성의태어가 해당 국가의 고유한 특 성을 반영하는 정서와 문화를 함께 이해하는 것이라고 밝힌 선행 연구와 일치한다고 볼 수 있다(Kim, 2015).

결과적으로, 본 연구의 다문화 가정 아동은 표준화 어휘검사와 부모보고를 통해 언어능력에서 한국어만을 사용하는 단일문화 가 정 아동과 비교하여 부족함이 없었음에도 불구하고, 의성의태어 과제 수행에서는 사물과제를 제외하고 집단 간 유의한 차이를 보였 다. 이는 한국 단일문화 가정의 경우 아동지향어의 특징을 지닌 의 성의태어를 자녀가 아주 어릴 때부터 상호작용 시 빈번하게 사용한 반면, 다문화 가정의 경우 한국 가정에 비해 의성의태어의 사용이 상대적으로 부족하기 때문인 것으로 보인다(Bae \& Park, 2012). 이 는 다문화 가정 어머니의 모국어인 베트남어에서 한국어에 비해 의 성의태어의 수와 사용이 적은 것에 기인한다(Bae \& Park, 2012). 한 국 단일문화 아동은 초기 아동기부터 어머니를 통해 자연스럽게 의성의태어에 노출되는 데에 비해, 다문화 가정의 아동은 상대적 으로 한국 아동에 비해 가정 내에서는 의성의태어의 노출이 적을 수 있다. 따라서, 한국에서 다양하게 활용되는 의성의태어는 한국 어를 모국어로 사용하지 않는 다문화 가정의 어머니 및 자녀들이 습득하기에 다소 어려울 수 있으나, 한국어에서의 의성의태어의 중 요성이 존재하므로, 급격한 언어발달이 이루어지는 초기 아동기 시 기에 의성의태어와 관련한 충분한 언어자극을 제공하고 관련 부모 교육 프로그램을 통해 다문화 가정의 자녀에게도 질적으로도 높 은 언어발달을 촉진하는 방안을 강구한다면 긍정적인 효과를 가져 올수 있을 것으로 보인다.

따라서 본 연구의 논의 및 결론을 토대로 한 제한점 및 후속연구 에 대한 제언은 다음과 같다. 첫째, 본 연구는 만 3세에서 6세까지 의 다문화 가정과 한국 가정 아동의 수를 연령별로 맞추었다. 그러 나 연령별 비교분석을 하기에 각 집단의 대상자 수가 적어 연령별 로 나누지 않고 하나로 묶어 차이를 살펴보았다. 따라서 후속연구 에서는 연령별 대상자 수를 늘린다면 연령별 비교분석이 가능할 것 이다. 또한 연령별 아동의 의성의태어 능력을 확인하여 추후 중재 프로그램 개발에 유용한 연구 방향을 제시할 수 있을 것이다. 둘째, 본 연구는 구조화된 과제를 사용하여 의성의태어의 사용 양상을 비교하였다. 후속연구에서는 이를 보완하여 부모와 아동 간의 실 제 의사소통 상황에서의 의성의태어 사용 양상에 대한 연구가 필 요할 것으로 보인다. 


\section{REFERENCES}

Bae, H. S. (2006). The study of teaching method about Korean onomatopoeic words and mimetic words for foreigner. Bilingual Research, 31, 97-122.

Bae, S. B., \& Park, H. W. (2012). The use of onomatopoeic language in Korean children-caregiver interactions. The Korean Journal of Developmental Psychology, 25(1), 101-115.

Choi, M. H., Jeong, M. R., \& Hwang, M. (2012). The production of case particles and semantic particles of Korean children from multicultural families and non-multicultural families. Korean Journal of Communication Disorders, 17(2), 307-321.

Cooper, R. P., \& Aslin, R. N. (1990). Preference for infant-directed speech in the first month after birth. Child Development, 61(5), 1584-1595.

Fernald, A. (1992). Meaningful melodies in mothers' speech to infants. In H. Papousek et al. (Eds.), Nonverbal vocal communication: comparative and developmental approaches (pp. 262-282). Cambridge: Cambridge University Press.

Fernald, A., Taeschner, T., Dunn, J., Papousek, M., de Boysson-Bardies, B., \& Fukui, I. (1989). A cross-language study of prosodic modifications in mothers' and fathers' speech to preverbal infants. Journal of Child Language, 16(3), 477-501.

Grieser, D. L., \& Kuhl, P. K. (1988). Maternal speech to infants in a tonal language: support for universal prosodic features in motherese. Developmental Psychology, 24(1), 14-20.

Han, J., \& Yim, D. (2018). Korean brief parent report measures of language development in children with vocabulary delay. Journal of Speech-Language \& Hearing Disorders, 27(2), 69-84.

Jang, J., Jeong, M., \& Hwang, M. (2014). Comprehending and defining homonyms in school-aged children from multicultural families. Communication Sciences \& Disorders, 19(1), 71-79.

Kambara, K., \& Tsukada, K. (2010). Onomatopen: painting using onomatopoeia. In H. S. Yang et al. (Eds.), Entertainment Computing - ICEC 2010 (pp. 43-54). Heidelberg: Springer.

Kim, H. M. (2015). A study on onomatopoeia and mimetic words for Korean language learners (Master's thesis). Yeungnam University, Gyeongsan, Korea.
Kim, Y. M., \& Yun, E. (2017). Exploring the meanings of usage about onomatopoeia and mimetic words in a child play situation. Korean Journal of Child Studies, 38(1), 63-76.

Kim, Y. T., Hong, G. H., Kim, K. H., Jang, H. S., \& Lee, J. Y. (2009). Receptive \& expressive vocabulary test (REVT). Seoul: Seoul Community Rehabilitation Center.

Kim, Y. T., Yang, M. S., \& Lim, W. J. (2014). The effect of the language education using onomatopoeia and mimetic words for the development-delayed children's expressive language. Korean Journal of Early Childhood Special Education, 14(4), 195-219.

Kwon, B. S., \& Cha, B. H. (2006). The impact of communication and cultural identity on marital satisfaction among Kosian housewives in rural areas. Korean Journal of Social Welfare, 58(3), 109-134.

Lee, J. (2016). A comparative study on word association between NS and NNS: based on the Korean onomatopoeic and mimetic words. Bilingual Research, 64, 157-186.

Mazuka, R., Kondo, T., \& Hayashi, A. (2008). Japanese mothers' use of specialized vocabulary in infant-directed speech: infant-directed vocabulary in Japanese. In N. Masataka (Eds.), The origins of language (pp. 39-58). Tokyo: Springer.

National Institute of the Korean Language. (1999). Korean dictionary. Seoul, Korea: Author.

Osaka, N. (1999). Kansei no Kotoba o Kenkyuu-suru: Giongo/Gitaigo ni Yomu Kokoro no Arika [Studying words of sensitivity: whereabouts of the mind explored in sound/manner mimetics]. Tokyo: Shinyosha.

Park, C. O., \& Lee, E. K. (2012). A comparative study of multicultural families mothers' educational view and perception of parenting roles for their young children. Journal of Multi-cultural Contents Studies, 12, 65-94.

Statistics Korea. (2018). 2017 Multicultural dynamics of population statistics. Retrieved from: https://www.gov.kr/portal/ntnadmNews/1679675

Taumoepeau, M., \& Ruffman, T. (2008). Stepping stones to others' minds: maternal talk relates to child mental state language and emotion understanding at 15, 24, and 33 months. Child Development, 79(2), 284-302.

Thiessen, E. D., Hill, E. A., \& Saffran, J. R. (2005). Infant-directed speech facilitates word segmentation. Infancy, 7(1), 53-71. 
Appendix 1. Onomatopoeic and mimetic wordlists of experimental tasks

\begin{tabular}{|c|c|c|c|c|c|c|}
\hline & \multirow{2}{*}{ No. } & \multirow{2}{*}{$\begin{array}{l}\text { Picture explaining task } \\
\text { (object) }\end{array}$} & \multicolumn{2}{|c|}{ Picture explaining task (sound-action) } & \multicolumn{2}{|c|}{ Association task } \\
\hline & & & V-K & Konly & V-K & Konly \\
\hline \multirow[t]{5}{*}{ Training words } & 1 & 밥 & 엉엉 & - & 쾅 & - \\
\hline & 2 & 연필 & 폴짝폴짝 & - & 엉엉 & - \\
\hline & 3 & 책 & 뒤뚱뒤뚱 & - & 꼭꼭 & - \\
\hline & 4 & 책상 & 반짝반짝 & - & 폴짝폴짝 & - \\
\hline & 5 & 의자 & 쾅 & - & 쓰담쓰담 & - \\
\hline \multirow[t]{15}{*}{ Test words } & 1 & 炫 & 쌩 & 부릉부릉 & 반짝반짝 & 부릉부릉 \\
\hline & 2 & 클레이(찰흙) & 탕탕 & 꿈틀꿈틀 & 쿨쿨 & 흥 \\
\hline & 3 & 수저 & 보슬보슬 & 흥 & 끈적끈적 & 꿈틀꿈틀 \\
\hline & 4 & 수건 & 후루룩(국물 마시는 것) & 꺄르르 & 엉금엉금 & 싹둑싹둑 \\
\hline & 5 & 컵 & 보글보글 & 싹둑싹둑 & 소곤소곤 & 까르르 \\
\hline & 6 & 인형 & 하하 & 뿡 & 구불구불 & 찰칵찰칵 \\
\hline & 7 & 문 & 멍멍 & 찰칵찰칵 & 빙글빙글 & 뿡 \\
\hline & 8 & 냄비 & 짹짹 & 끅(트림) & 길쭉길쭉 & 끅 \\
\hline & 9 & 신발 & 졸졸 & 뻥 & 지글지글 & 뽀글뽀글 \\
\hline & 10 & 고추 & 빙글빙글 & 아작아작(과자 먹는 것) & 데굴데굴 & 아작아작 \\
\hline & 11 & 사탕 & 쿨쿨 & 뽀글뽀글 & 따끔따끔 & 뻥 \\
\hline & 12 & 가방 & 엉금엉금 & 뿌지직 & 주륵주륵 & 뿌지직 \\
\hline & 13 & 사과 & 끄덕끄덕 & 뚝딱뚝딱 & 펄럭펄럭 & 치카치카 \\
\hline & 14 & 지우개 & 따끔따끔 & 딩동 & 끄덕끄덕 & 딩동 \\
\hline & 15 & 풍선 & 구불구불 & 치카치카 & 꿀꺽꿀꺽 & 뚝딱뚝딱 \\
\hline
\end{tabular}

V-K=Vietnamese-Korean bilingual; $\mathrm{K}$ only=Korean only. 


\section{국문초록}

\section{베트남어-한국어사용 다문화 가정과 한국 가정의 의성의태어 사용 비교} 김선경 · 유수화 · 장지혜 · 조윤주 · 양윤희 · 임동선

이화여자대학교 언어병리학과

배경 및 목적: 본 연구에서는 베트남어-한국어 이중언어 및 한국어 단일언어를 사용하는 어머니와 자녀의 의성의태어 사용 양상의 차 이를 알아보고자 하였다. 방법: 베트남어-한국어를 사용하는 다문화 아동 13 명, 어머니 8 명, 한국어를 사용하는 한국인 아동 14 명, 어 머니 11명이 참여하였다. 아동들은 만 3-6세로, 표준화 검사로 측정한 어휘능력에 집단 간 차이는 없었다. 본 연구에서는 그림설명과제 (사물, 소리동작)와 연상과제가 사용되었다. 결과: 다문화 가정의 어머니는 한국어만을 사용하는 단일문화 가정의 어머니에 비해 그림 설명과제(사물, 소리동작)에서 유의하게 낮은 수행을 보였다. 그러나, 다문화 가정 및 단일문화 가정 아동의 사물을 설명하는 그림과제 수행에는 유의한 차이가 나타나지 않았으며, 소리동작을 설명하는 그림과제 수행에서는 다문화 가정 아동이 단일문화 가정의 아동보 다 낮은 수행을 보였다. 연상과제에서는 다문화 및 단일문화 가정의 어머니 및 아동 모두 정확도와 반응속도에서 유의한 차이를 보였다. 논의 및 결론: 다문화 가정과 단일문화 가정 아동은 표준화 어휘검사 결과에서 유의한 차이가 나타나지 않았지만, 두 집단의 어머니와 아동 모두는 의성의태어 능력에서 유의한 차이를 보였다. 한국어에서의 의성의태어는 특히 초기 아동기 시기에 중요한 특징을 지니며, 다문화 가정 아동의 언어발달을 촉진하는 데에 의성의태어가 높은 가치를 지니고 있을 것으로 보인다.

핵심어: 의성어, 의태어, 베트남어-한국어사용 다문화 가정, 한국어사용 단일문화 가정, 엄마의 언어능력

본 논문은 2018년 대한민국 교육부와 한국연구재단의 지원을 받아 수행된 연구임(No. NRF-2018S1A3A2075274).

\section{참고문헌}

국립국어원(1999). 표준국어대사전. 서울: 국립국어원.

권복순, 차보현(2006). 농촌지역 코시안가정주부의 의사소통능력, 문화적 정체성이 결혼만족도에 미치는 영향 한국사회복지학, 58(3), 109-134.

김영태, 홍경훈, 김경희, 장혜성, 이주연(2009). 수용·표현어휘력검사(REVT). 서울: 서울장애인종합복지관.

김윤미, 윤은주(2017). 유아 놀이에서 의성어.의태어 사용 의미 탐구. Korean Journal of Child Studies, 38(1), 63-76.

김윤태, 양미선, 임완정(2014). 의성어.의태어를 이용한 언어교육이 발달지체 유아의 표현언어에 미치는 영향 유아특수교육연구, 14(4), 195-219.

김홍매(2015). 한국어 학습자를 위한 의성·의태어 연구. 영남대학교 대학원 석사학위논문.

박찬옥, 이은경(2012). 출신 국가별 다문화가정 어머니의 자녀 교육관 및 부모역할 인식. 다문화콘텐츠연구, 12, 65-94.

배성봉, 박혜원(2012). 한국아동의 의성어와 의태어 사용. 한국심리학회지: 발달, 25(1), 101-115.

배현숙(2006). 외국인을 위한 한국어 의성어, 의태어 교수법 연구. 이중언어학, 31, 97-121.

이지은(2016). 한국어 모국어 화자와 비모국어 화자간의 의성어, 의태어 연상 내용 비교 연구. 이중언어학, 64, 157-186.

장종윤, 정미란, 황민아(2014). 초등학교 저학년 다문화가정 아동의 동음이의어 이해와 정의하기. Communication Sciences \& Disorders, 19(1), 71-79. 최미현, 정미란, 황민아(2012). 학령 전 다문화가정 아동과 일반가정 아동의 격조사와 보조사산출. 언어청각장애연구, 17(2), 307-321.

통계청(2018). 2017 다문화인구동태 통계.https://www.gov.kr/portal/ntnadmNews/1679675

한지윤, 임동선(2018). 부모 보고형 아동 언어 능력 평가도구(KBPR)의 표준화를 위한 예비연구. 언어치료연구, 27(2), 69-84.

\section{ORCID}

김선경(https://orcid. org/0000-0003-0076-4695); 유수화(https://orcid.org/0000-0001-5189-4161); 장지혜(https://orcid.org/0000-0002-5011-7341); 조윤주(https://orcid.org/0000-0001-7526-0358); 양윤희(https://orcid.org/0000-0003-3240-5996); 임동선(https://orcid.org/0000-0001-8254-9504) 